\title{
Syncope: A rare presentation of Cervical spondylosis
}

\author{
Sudhir Kumar Verma ${ }^{1}$, Mohammad Yaseen ${ }^{2}$, Vinay Bharadwaj ${ }^{3}$,Aslam Pasha ${ }^{4}$ \\ 1,2,3,4 Assistant Professor, Department of General Medicine, Career institute of Medical Sciences \& Hospital, \\ Lucknow ,U.P, India
}

\begin{abstract}
Cervical spondylosis commonly presents with its classical symptoms of intermittent neck \& shoulder pain, headache with or without neurological deficit. Syncope has been reported in a very few cases of cervical spondylosis. Although rare, syncope and vertigo whenever present in Cervical spondylosis is usually preceded by its classical symptoms. When a patient presents with syncope and vertigo in the absence of other classical symptoms of cervical spondylosis, it is difficult to consider the possibility of cervical spondylosis which may result in delayed diagnosis and further progression of disease. Here, we report a case of 55 years old man who presented to us with syncope and recurrent episodes of vertigo only which on work up was diagnosed as a case of cervical spondylosis.
\end{abstract}

Keywords: Cervical spondylosis, syncope, vertigo, vertebrobasilar insufficiency.

\section{Introduction}

Cervical spondylosis(CS) is one of the commonly encountered clinical entity. It is slightly more common in males. ${ }^{1}$ It can be asymptomatic but once symptomatic it mostly presents with its classical symptoms of intermittent neck \& shoulder pain, headache with or without neurological deficit. ${ }^{2}$ Syncope and vertigo are very uncommon manifestations of CS \& whenever present, is usually preceded by its classical symptoms. We present here a 55-year-old obese man who presented to us with a single episode of syncope followed by recurrent episodes of vertigo for last one day, which later on was diagnosed as a case of cervical spondylosis.

This case is important because it is easy to diagnose CS when a patient presents with its classical symptoms. However, when a patient presents with syncope and vertigo only, it is difficult to consider CS as differential diagnosis which may result in delayed diagnosis and further progression of disease.

\section{Case presentation}

A 55 years old man presented to us with a single episode of transient loss of consciousness and recurrent episodes of vertigo for one day. Unconsciousness lasted for 2-3 minutes followed by spontaneous recovery. There was no abnormal movements, frothing, tongue bite or urinary incontinence during the episode of unconsciousness. After gaining consciousness, he had recurrent episodes of vertigo which got aggravated on rotating head to right side. The patient did not have complaints of neck \& shoulder pain, headache, tingling, numbness or motor weakness of extremities, tinnitus, hearing impairment, intake of ototoxic drugs, diplopia, dysphagia, palpitation, breathlessness or chest pain. Patient was a chronic smoker for 30 years. Family history was non-significant. There was no history of diabetes mellitus, hypertension or trauma in the recent past.

On general examination, pulse was 76/minute, regular; blood pressure was 154/90 $\mathrm{mm} \mathrm{Hg}$ in right arm supine position; temperature $98.2^{\circ} \mathrm{F}$, respiratory rate 14 /minute with no icterus, pallor, cyanosis and pedal oedema. Nervous system examination revealed that higher mental functions were normal. All cranial nerves were intact. Fundus examination was normal. Sensory examination did not reveal any abnormality. Power was $5 / 5$ in all four limbs on Medical Research Council scale. All superficial and deep tendon reflexes were normal. A horizontal nystagmus with fast component towards the right side was present. There were no other signs suggestive of cerebellar involvement. Spurling sign \& Romberg test was negative. Rest of systemic examination did not reveal any abnormality. Benign paroxysmal positional vertigo and other peripheral causes of vertigo were excluded by the otorhinolaryngologist.

\section{Investigations}

Investigations revealed: Hemoglobin- $14.7 \mathrm{~g} / \mathrm{dl}$, total leucocyte count- $6300 / \mathrm{mm}^{3}$,platelet counts2.6lacs $/ \mathrm{mm}^{3}$,random blood sugar- $147.2 \mathrm{mg} / \mathrm{dl}$, blood urea- $18.7 \mathrm{mg} / \mathrm{dl}$, serum creatinine- $0.6 \mathrm{mg} / \mathrm{dl}$. Fasting lipid profile showed total cholesterol- $204 \mathrm{mg} / \mathrm{dl}$, LDL cholesterol- $176 \mathrm{mg} / \mathrm{dl}$, triglyceride- $222 \mathrm{mg} / \mathrm{dl}$ and HDL cholesterol of $46.1 \mathrm{mg} / \mathrm{dl}$. MRI of head was normal. Electrocardiography showed left ventricular hypertrophy. Xray chest postero-anterior view was normal. His X-ray cervical spine antero-posterior and lateral view showed loss of cervical lordosis, osteophytic outgrowth at C5 and C6 vertebra (Fig.1). 
Figure 1

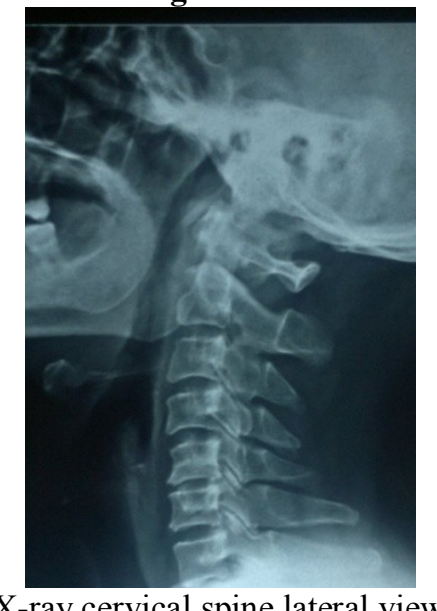

Medical resonance imaging of cervical spine(Fig.2) revealed loss of cervical lordotic curvature with disc bulge at C5-C6 level with thecal indentation \& narrowing of lateral recesses.

Figure 2

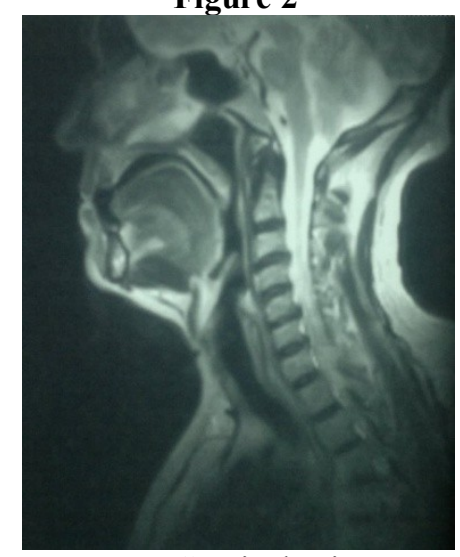

MRI Cervical spine

Doppler ultrasonography of vertebral arteries showed tortuous right vertebral artery with mildly elevated velocities (Table1)

Table 1

\begin{tabular}{|l|l|l|}
\hline Flow velocity & $\begin{array}{l}\text { Right vertebral } \\
\text { artery }(\mathrm{cm} / \mathrm{s})\end{array}$ & $\begin{array}{l}\text { Left vertebral artery } \\
(\mathrm{cm} / \mathrm{s})\end{array}$ \\
\hline $\begin{array}{l}\text { Peak systolic } \\
\text { velocity }\end{array}$ & 76 & 46 \\
\hline $\begin{array}{l}\text { End diastolic } \\
\text { velocity }\end{array}$ & 27 & 18 \\
\hline
\end{tabular}

Doppler ultrasonographic velocities of the vertebral arteries

\section{Treatment \& Follow up}

He was managed conservatively with hard cervical collar, acelofenac 100mg twice daily, thiocolchicoside $4 \mathrm{mg}$ twice daily, prochlorperazine maleate $5 \mathrm{mg}$ three times daily, amlodipine $5 \mathrm{mg}$ once daily and atorvastatin $10 \mathrm{mg}$ once daily. After 2 -weeks of conservative treatment he had complete resolution of symptoms.

\section{Discussion} mechanisms. $^{3}$

Vertigo and syncope in a patient of cervical spondylosis has been attributed to many causes and several 1.Vasogenic: The vertebrobasilar circulation supplies the vestibular labyrinth, VIII nerve, brain stem, cerebellum and occipital lobes. ${ }^{4}$ Cervical osteophytes can press on the vertebral artery causing its occlusion during head turning to the same or opposite side. ${ }^{5,6}$, 
2.Neurogenic: Afferent impulses from the neck travel via posterior cervical roots to the vestibular nuclei. In cervical spondylosis, alteration in the cervical afferent flow may be due to the pressure on the cervical nerve roots by disc protrusions. ${ }^{7}$

Till now, very few cases presenting with vertigo and syncope resulting from vascular risk factors, cervical spondylosis, and head rotation have been reported in the literature. ${ }^{9,10,11,12}$ Our patient presented with single episode of syncope followed by recurrent episodes of vertigo aggravated by head rotation to the right side. Patient also had multiple vascular risk factors like obesity, dyslipidemia, smoking and hypertension. It is likely that cervical osteophytes pressed on the atherosclerosed vertebral arteries and there was no sufficient collateral flow ${ }^{10,11,12}$ which produced symptoms in our patient.

The use of cervical collar and anti-inflammatory medications reduced the friction and inflammation between the osteophytes and the vertebral arteries and prevented the possible vertebral artery occlusion. Atherosclerosis was stabilized by the statin and the antihypertensives which controlled the blood pressure. Conservative therapy led to complete resolution of their symptoms.

\section{Conclusion}

It is easy to diagnose cervical spondylosis when a patient presents with its classical symptoms of intermittent neck \& shoulder pain, headache and neurological deficit. However, when a patient presents with syncope and vertigo only, it is difficult to consider CS as differential diagnosis which may result in delayed diagnosis and further progression of disease. So, one should always keep the differential diagnosis of cervical spondylosis in a patient with cardiovascular risk factors presenting with syncope and vertigo only.

\section{References}

[1]. D H Irvine, J B Foster, D J Newell, B N Klukvin. Prevalence of cervical spondylosis in a general practice. Lancet,14,1965, 1089-92

[2]. B M McCormack, P R Weinstein. Cervical spondylosis. An update. West J Med ,165(1-2), 1996; : 43-51

[3]. T Brandt, R W Baloh. Rotational vertebral artery occlusion: a clinical entity or various syndromes, Neurology,65, 2005;:1156-7.

[4]. CFO Mahoney. Causes of balance disorders. Scotts Brown's Otolaryngology 2(6),1997

[5]. OGB Nwaorgu. Nigerian Journal of Medicine ,12(3),2003

[6]. M Mazloum,F Samini. Evaluation of the results of surgical and medicaltreatment in 16 patients with vertigo secondary tocervical spondylosis Medical Journal of Islamic Republic of Iran 2006,20(2)

[7]. M Wilkinson. Practitioner 1970; 204

[8]. K R Bulsara, D A Velez, A Villavicencio. Rotational vertebral artery insufficiency resulting from cervical spondylosis: case report and review of the literature, Surg Neurol,65, 2006,625-7.

[9]. J Olszewski, J Majak, P Pietkiewicz et al. The association between positional vertebral and basilar artery flow lesion and prevalence of vertigo in patients with cervical spondylosis. Otolaryngol Head Neck Surg, 134, 2006:680-4.

[10]. T Kuether, GM Nesbit, WM Clarke, et al. Rotational Vertebral Artery Occlusion: A Mechanism of Vertebrobasilar Insufficiency. Neurosurgery, 41,1997,427-33.

[11]. M Ogino, T Kawamoto,K Asakuno et al. Proper management of the rotational vertebral artery occlusion secondary to spondylosis, Clin Neurol Neurosurg, 103,2001,250-3.

[12]. B Cagnie, E Barbaix , E Vinck et al. Extrinsic risk factors for compromised blood flow in the vertebral artery: anatomical observations of the transverse foramina from C3 to C7,Surg Radiol Anat ,27,2005,312-6. 